\title{
MOISTURE AND HEAT BUDGETS OF A CIRRUS CLOUD FROM AIRCRAFT MEASUREMENTS DURING FIRE
}

\author{
Ismail GULTEPE and Andrew HEYMSFIELD \\ National Center For Atmospheric Research ${ }^{1}$ \\ P.O. Box 3000 \\ Boulder, Colorado 80307
}

\section{INTRODUCTION}

Increasing knowledge of cirrus cloud properties can contribute to general circulation model development and ultimately to a better understanding of climate. The objective of this study is to gain a better understanding of cirrus cloud characteristics. Observations from different sensors during the FIRE (First ISCCP (International Satellite Cloud Climatology Program) Regional Experiment) which took place in Wisconsin over Oshkosh (Starr, 1987) together with pertinent calculations will be used to understand the dynamical, microphysical, and radiative characteristics of these clouds.

\section{SYNOPTIC CONDITIONS}

Cirrus clouds on 31 October over Wisconsin formed in a thermally stable atmosphere. A cold front moved over the Wisconsin region at 0600 UTC. The winds were averaging 50

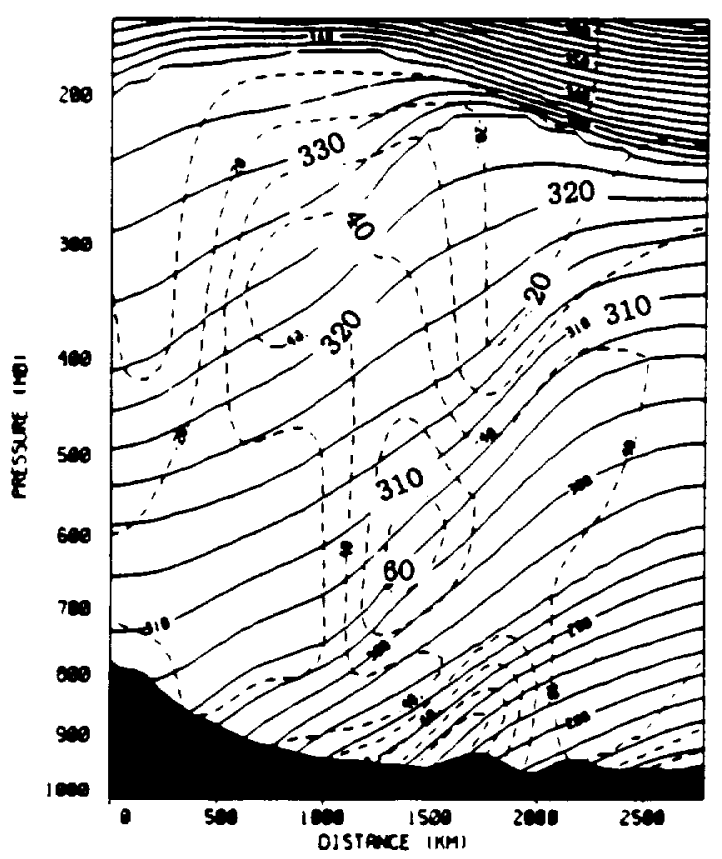

Figure 1. A cross section parallel to the jet stream at 12:00 UTC on 31 October 1986. Wisconsin region is between 1500 and $2000 \mathrm{~km}$. The solid lines are for isentropic surfaces and the dashed lines are for relative humidity with respect to water.

1 The National Center for Atmospheric Research is sponsored by the National Science Foundation. 
$\mathrm{m} \mathrm{s}^{-1}$ at $300 \mathrm{mb}$ at 1200 UTC over Wisconsin. There was a weak upper level trough which deepened at 0000 UTC on 1 November. The cirrus cloud was situated between 400 and $300 \mathrm{mb}$ over Wisconsin approximately between $1400 \mathrm{UTC}$ and 1830 UTC on 31 October. Moisture advection from the southwest probably played an important role in the cirrus formation (see Figure 1) over Wisconsin.

\section{MEASUREMENTS}

The data for this research were taken by the NCAR King Air and rawinsondes on 31 October 1986 over Oshkosh. The primary measurements from the NCAR King Air were ice crystal concentration, size, habit, temperature, pressure, dew point, horizontal and vertical wind speed and direction, and infrared and solar radiances. The raw measurements were available for calculations at a rate of $1 \mathrm{~Hz}$.

Two different flight patterns are used in this study: the first is the step-up maneuver and the second is the Lagrangian descent maneuver. The length of each constant altitude penetration was about $30 \mathrm{~km}$ and the separation in the vertical between two penetrations was about $300 \mathrm{~m}$. The second maneuver called the Lagrangian spiral descent covered a time period of about 20 minutes (1616-1633 UTC for spiral I and 1657-1720 UTC for spiral II) for an entire cloud sounding on 31 October 1986. During these spirals, the aircraft descent rate was about $1.5 \mathrm{~m} \mathrm{~s}^{-1}$.

\section{METHODS OF ANALYSIS}

In this section, the moisture and heat budget equations including internal sources (e.g., ice crystal growth) and external sources (e.g., radiative flux divergence) are given. The most important parameter in the budget equations is vertical velocity $w$. Therefore, first we explain its calculation in the following subsection. Then, different terms (e.g., advection and turbulent flux divergence) in the budget equations are discussed.

a. Vertical velocity calculation from hydrometeor data

Vertical velocity $w$ used in the budget equations is calculated from the particle size spectra measurements. The simultaneous solution technique (Heymsfield, 1977) is used to obtain $w$. This technique requires the following terms derived from the PMS 2D$C$ probe measurements: ice water content (IWC), precipitation rate (PR), and terminal velocity $\left(V_{t}\right)$ which are all dependent on habit. This technique does not need dew point temperature measurements.

\section{b. Moisture budget calculation}

The moisture budget for a cirrus cloud is calculated from the continuity equation of the water vapor mixing ratio. To the equations used by Wilfried (1984), we add two more terms: the vertical turbulent flux of the moisture and the ice crystal growth rate, and write the equation as:

$$
\frac{\partial q}{\partial t}+\bar{U} \frac{\partial q}{\partial s}+\bar{w} \frac{\partial q}{\partial z}+\frac{\partial \overline{w^{\prime} q^{\prime}}}{\partial z}+\frac{\partial w_{i}}{\partial t} \frac{1}{\rho_{\mathrm{a}}}=0
$$

where $t$ is the time, $q$ the vapor mixing ratio, $s$ the length along the aircraft longitudinal axis, $z$ altitude. In Equation (1), the first term is the local change of the vapor mixing ratio, the second the horizontal advection, the third the vertical advection, the fourth the divergence of the turbulent moisture flux, and the last term the loss of moisture because 
of the growth of ice crystals $\left(\frac{\theta w_{i}}{\theta t}\right)$. The first term is calculated from two Lagrangian spiral descents which are separated from each other by approximately 43 minutes. The second term is obtained from the product of the longitudinal wind $\bar{U}$ with respect to cloud and the change of the mixing ratio over the constant flight leg. The $\bar{w}$ in the third term is average vertical velocity. Perturbations $\left(e . g ., w^{\prime}\right)$ are obtained from the measured $(w)$ by substracting the average $(e . g ., \bar{w})$. The $\frac{\partial q}{\partial z}$ is obtained from $q$ at two constant altitudes (from the step-up maneuver). The fourth term is calculated from the vertical variation of the turbulent flux at two constant altitudes. The depletion of vapor from the environment because of ice crystal growth is determined from equations given by Heymsfield (1975). The $\rho_{a}$ in the last term is air density.

c. Heat budget calculation

The calculation of the heat budget of a cirrus cloud is also obtained from the continuity equations used by Telford and Warner (1964) with four additional terms as follows:

$$
\frac{\partial \theta}{\partial t}+\bar{U} \frac{\partial \theta}{\partial s}+\bar{w} \frac{\partial \theta}{\partial z}+\frac{\partial \overline{w^{\prime} \theta^{\prime}}}{\partial z}+\left(\frac{\partial \theta}{\partial t}\right)_{I R}+\left(\frac{\partial \theta}{\partial t}\right)_{S W}+\frac{\partial w_{i}}{\partial t} \frac{L_{\varepsilon}}{\rho_{a} C_{p}}=0
$$

where the first term is the local change of potential temperature $\theta$, the second the horizontal temperature advection, the third the vertical temperature advection, the fourth the vertical divergence of temperature flux. The fifth and sixth respectively are the local change of temperature due to the IR and SW radiative fluxes and the last term the latent heat release because of the ice crystal growth. In this term, $L_{\text {a }}$ is the latent heat of sublimation and $C_{p}$ the specific heat at constant pressure. The first term is obtained from the Lagrangian spiral descent profiles as discussed previously for the moisture budget. The over bar in (2) signifies the constant altitude flight leg $(30 \mathrm{~km})$ averages of the various parameters. The radiative cooling rate due to the IR and SW radiative flux divergences is calculated from the IR and SW upward and downward looking radiometers. The radiative cooling rate is obtained from the following equation (Welch et al., 1980):

$$
\left(\frac{\partial \theta}{\partial t}\right)_{I R, S W}=-\frac{\left(\frac{\partial F}{\theta z}\right)_{I R, S W}}{C_{p} \rho_{a}}
$$

where $F$ is measured irradiance.

\section{RESULTS AND CONCLUSIONS}

a. Relative importance of the moisture budget terms

The moisture budget of the cirrus on 31 October is calculated from (1). The terms used in (1) are the local change, horizontal and vertical advections, turbulent flux divergence, and ice crystal growth terms.

The values of the terms in the moisture budget equations are shown in Table 1 . The layers from I to $V$ in this table are between 7.9 and $9.4 \mathrm{~km}$ altitude with a vertical separation approximately $300 \mathrm{~m}$. The negative (positive) sign indicates the moisture convergence (divergence) due to the advection. Moisture convergence is seen at low levels. At the upper levels, moisture divergence is more important. The sum of the terms in the layers, 
excluding the local change term, gives a divergence of $0.031 \mathrm{mg} \mathrm{kg}^{-1} \mathrm{~s}^{-1}$ which is very close to the local change term. Moisture convergence is seen at layers II, III, and IV. The sum of the vertical moisture advection values results in a convergence of about $-0.095 \mathrm{mg}$ $\mathrm{kg}^{-1} \mathrm{~s}^{-1}$. Turbulent flux divergence is one order of magnitude lower than other terms in the moisture budget equation. Turbulent flux divergence values add to about $0.003 \mathrm{mg}$ $\mathrm{kg}^{-1} \mathrm{~s}^{-1}$. As a negative source (moisture divergence), ice crystal growth plays relatively an important role on the expenditure of vapor from the environment at mid-layers. The small residual value of about $0.002 \mathrm{mg} \mathrm{kg}^{-1} \mathrm{~s}^{-1}$ is probably due to errors in the wind component and the dew point measurements.

b. Relative importance of the heat budget terms

The heat budget of the cirrus cloud on 31 October is calculated from (2). The terms in the heat budget equation (see Table 2) are the local change, horizontal and vertical advection, turbulent flux divergence, ice crystal growth rate, and IR and SW flux divergence. A layer number in this table has the same meaning for those used in Table 1.

Negative values of the terms used in this section will represent cooling in the cirrus layers. Cold air advection in the lowest layer is about $8^{\circ} \mathrm{C} \mathrm{day}{ }^{-1}$. Warm air advection is seen in layers III and V. The net warming due to the horizontal advection term through the layer is found to be about $0.5^{\circ} \mathrm{C}$ day $^{-1}$. The vertical heat advection is the most important term in the heat budget equation. Values of the turbulent flux divergence and ice crystal growth terms are about the same, but they are much smaller than the other terms in (2). The magnitude of the growth term for the entire cirrus is greater than that of the absolute radiative flux divergence terms in (2). The IR cooling rate shows that the cirrus cloud is warming at cloud base with cooling in the upper levels. The maximum cooling rate is found to be about $14^{\circ} \mathrm{C}$ day $^{-1}$ in layers III and IV, and warming about $7^{\circ} \mathrm{C}_{\text {day }}{ }^{-1}$ in layer I. The IR cooling rate for the entire cirrus cloud is about $5^{\circ} \mathrm{C}_{\text {day }}{ }^{-1}$. The $\mathrm{SW}$ cooling rate shows that the cirrus is cooling at cloud top and base. At mid-levels, a warming of about $8^{\circ} \mathrm{C} \mathrm{day}^{-1}$ and a similar cooling occurs in the adjacent layers. The sum of the IR and SW cooling rates for the entire cirrus cloud shows that the net cooling is about $1.1^{\circ} \mathrm{C}$ day $^{-1}$. Error in IR and SW irradiance measurements can be as much as $15 \%$ and $50 \%$, respectively. The residual of about $7.0 \times 10^{-4}{ }^{\circ} \mathrm{C} \mathrm{s}^{-1}$ between the local cooling rate and the sum of the other terms in (2) can be attributed to errors in the aircraft measurements.

Overall, it appears that the dynamic characteristics of the environment play a crucial role in the structure of the cirrus cloud. The IR cooling rate and release of latent heat are important in the upper layers, indicating higher ice crystal growth rates.

\section{REFERENCES}

Heymsfield, A.J., 1975: Cirrus uncinus generating cells and the evolution of cirriform clouds. Part I: Aircraft measurements of the growth of the ice phase. J. Atmos. Sci., $32,789-808$.

-, 1977: Precipitation development in stratiform ice clouds: A microphysical and dynamical study. J. Atmos. Sci., 34, 367-381.

Kahn, P.M., and H.K. Weickmann, 1969: High altitude radiometric measurements of cirrus. J. Appl. Meteor., 147-154.

Starr, D. O'C. 1987: A cirrus cloud experiment: Intensive field observations planned for FIRE. Bull. Amer. Meteor. Soc., 68, 119-124. 
Telford, J.W., and J. Warner, 1964: Fluxes of heat and vapor in the lower atmosphere derived from aircraft observations. J. Atmos. Sci., 21, 539-548.

Welch, R.M, S.K. Cox, and W.G. Zdunkowski, 1980: Calculations of the variability of ice cloud radiative properties at selected solar wavelengths. Appl. Opt., 19, 3057-3066.

Wilfried, B., 1984: Evaporation Into the Atmosphere. Published by D. Reidel Publishing Company, P.O. Box 17, 3300 AA Dordrecht Holland, 293 pp.

Table 1. The terms used in the moisture budget equation except the local cooling rate (see text for detailed discussion).

\begin{tabular}{ccccc}
\hline LAYER & $U \frac{\Delta g}{\Delta g}$ & $\bar{w} \frac{\Delta \bar{q}}{\Delta z}$ & $\frac{1}{\rho_{a}} \frac{\Delta w_{t}}{\Delta t}$ & $\begin{array}{c}\frac{\Delta\left(\overline{w^{\prime} q^{\prime}}\right)}{\Delta z} \\
\end{array}$ \\
{$\left[\mathrm{mg} \mathrm{kg}^{-1} \mathrm{sec}^{-1}\right]$} & {$\left[\mathrm{mg} \mathrm{kg}^{-1} \mathrm{sec}^{-1}\right]$} & {$\left[\mathrm{mg} \mathrm{kg}^{-1} \mathrm{sec}^{-1}\right]$} & {$\left[\mathrm{mg} \mathrm{kg}^{-1} \mathrm{sec}^{-1}\right]$} \\
\hline & & & & \\
I & -0.04 & 0.003 & 0.0062 & -0.0098 \\
II & -0.018 & -0.041 & 0.0073 & 0.0057 \\
III & 0.05 & -0.028 & 0.0056 & 0.0047 \\
IV & 0.031 & -0.049 & 0.0053 & -0.0023 \\
V & 0.008 & 0.020 & 0.0034 & 0.0054 \\
\hline TOTAL & 0.031 & -0.095 & 0.0284 & 0.003 \\
\hline
\end{tabular}

Table 2. The terms used in the heat budget equation except the local cooling rate (see text for detailed discussion).

\begin{tabular}{|c|c|c|c|c|c|c|}
\hline LAYER & $\begin{array}{c}\bar{U} \frac{\partial \theta}{\Delta,} \times 10^{-4} \\
{\left[{ }^{\circ} \mathrm{C} \sec ^{-1}\right]}\end{array}$ & $\begin{array}{l}\bar{w} \frac{\Delta \bar{\theta}}{\Delta x} \times 10^{-1} \\
{\left[{ }^{\circ} \mathrm{C} \sec ^{-1}\right]}\end{array}$ & $\begin{array}{l}\frac{\Delta \overline{w^{\prime} \theta}}{\Delta z} \times 10^{-4} \\
{\left[{ }^{\circ} \mathrm{C} \sec ^{-1} !\right.}\end{array}$ & $\begin{array}{l}\frac{L \cdot \frac{\Delta \bar{\alpha}}{\bar{\lambda} \mid}}{C, \rho_{n n}} \times 10^{-1} \\
{\left[{ }^{\circ} \mathrm{C} \sec ^{-1} !\right.}\end{array}$ & 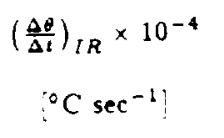 & $\begin{array}{c}\left(\frac{\Delta \theta}{\Delta t}\right)_{S W} \times 10^{-4} \\
!^{\circ} \mathrm{C} \mathrm{sec}-1 !\end{array}$ \\
\hline I & -0.94 & -1.31 & 0.20 & 0.18 & 0.80 & -0.19 \\
\hline II & -0.1 & -3.10 & 0.04 & 0.21 & -1.39 & 1.05 \\
\hline III & 0.29 & -4.40 & -0.07 & 0.16 & 1.50 & -0.98 \\
\hline IV & 0.05 & -6.09 & 0.14 & 0.17 & -1.45 & 0.97 \\
\hline $\mathrm{v}$ & 0.85 & -2.59 & 0.01 & 0.10 & -0.06 & -0.38 \\
\hline TOTAL & 0.05 & -17.50 & 0.32 & 0.82 & -0.60 & 0.47 \\
\hline
\end{tabular}


